\title{
Unilateral Biportal Endoscopic Lumbar Interbody Fusion. Technical Note and Surgical Comparison with Conventional MIS TLIF.
}

\section{Asrafi Rizki Gatam ( $\nabla$ rizki.gatam@gmail.com )}

Rumah Sakit Umum Pusat Fatmawati https://orcid.org/0000-0002-9457-7243

\section{Omar Luthfi}

Rumah Sakit Umum Adhyaksa

\section{Harmantya Mahadhipta}

Rumah Sakit Umum Kabupaten Tangerang

\section{Luthfi Gatam}

Rumah Sakit Umum Pusat Fatmawati

\section{Ajiantoro Ajiantoro}

Rumah Sakit Premier Bintaro

\section{Technical note}

Keywords: Unilateral biportal endoscopy, Lumbar interbody fusion, Minimal invasive spine surgery, Full endoscopic spine surgery, Degenerative spondylolisthesis

Posted Date: May 26th, 2020

DOI: https://doi.org/10.21203/rs.3.rs-29086/v1

License: (1) This work is licensed under a Creative Commons Attribution 4.0 International License. Read Full License 


\section{Abstract}

Backgrounds : Minimally invasive surgery develops very extensively in past few decades, not only in the scope of decompression but until fusion surgery. Surgeon has been trying to reduce the damage to the normal anatomical structure. In this study we performed unilateral biportal endoscopic lumbar interbody fusion (ULIF) as one of the fusion option which is readily available without sophisticated minimal invasive instrument. The purpose of this study is to introduce unilateral biportal endoscopic surgery and comparing the result with conventional minimal invasive lumbar interbody fusion (MISTLIF)

Methods : This is a retrospective cohort study of 145 lumbar spondylolisthesis patient underwent conventional MIS-TLIF or ULIF procedure. All patient were followed up until 12 months to evaluate the VAS of back pain and leg pain, ODI, SF-36 and fusion rate.

Results : Back pain VAS were a little higher compared with the endoscopic group, but the VAS of leg pain were the same. Both group had improvement in ODI score and SF-36 which shows both of the procedure were quite effective in managing such cases.

Conclusion : Full endoscopic fusion offer benefit of minimal invasive surgery with better visualization of decompression and endplate preparation. Long term follow up is still needed to evaluate the result of the procedure.

\section{Introduction}

The technique of lumbar interbody fusion has developed extensively since the last three decades. Conventional open surgery, in which set as the gold standard in the 80 's, slowly replaced by the more minimal invasive procedure to get better outcome and better patient satisfaction.[1] Minimal invasive technique had been proven to have less destruction in the posterior anatomical structure such as muscles, ligaments and the bone itself.[2] Even though decompression using full endoscopic technique had been proven to have a lot of advantages compared with conventional technique, but the evidence for fusion are still lacking.[3, 4]

Full endoscopic lumbar fusion spine surgery start to steal the popularity among spine surgeon, as with endoscopy we can prepare the endplate better by seeing directly the endplate plate itself to get better fusion result.[5-8] Recently, there are several technique for endoscopic lumbar interbody fusion, in terms of approach, surgeons can choose either transforaminal or interlaminar approach. The transforaminal approach is done quite similar with uniportal percutaneous endoscopic discectomy with or without superior articular process resection continued with endplate resection and cage insertion. $[5,9]$ This technique allows fusion with stand alone cage or in combination with supplemental pedicle screw insertion.[9] The problem with this technique is preparation the endplate because the endoscope is relatively fixed and unmovable, there are question among surgeon whether preparation is good enough to make good fusion bed.

The interlaminar approach for fusion can be done using either biportal endoscopic or uniportal endoscopic technique.[10, 11] The endoscopic views of both procedure are quite easy to interpret compared with transforaminal approach, especially for surgeons who are familiar with open surgery or microscopic surgery. The biportal technique has advantages of zero investment by using standard arthroscopic lenses either $0^{\circ}, 30^{\circ}$ or even $70^{\circ}$ angle, more mobility, wide viewing angle and open surgery instrument such as Kerrison punch, forceps, endplate curretes and etc which are usually already available in the hospital performing orthopaedic and spine surgery.[12,13] The main disadvantages of is having two portals instead of one, in which some of the surgeon think of more soft tissue injury compared with uniportal technique.

The fusion rate for endoscopic lumbar interbody fusion remain controversial, most of the senior surgeon in Indonesia who has been performing the conventional procedure for decades don't really believe in the endoscopic fusion procedure, even though some of research showed good to excellent fusion within 12 months after the procedure. In this paper we would like 
to share our technique for unilateral biportal endoscopic lumbar interbody fusion (ULIF) and compare the result with conventional minimal invasive transforaminal interbody fusion (MIS-TLIF).

\section{Materials And Methods}

This is a retrospective cohort non-inferiority study conducted on three hospital in Jakarta, Indonesia. Data were collected from January 2016-April 2020; all patients were followed up until one year duration. On that period, we found 202 patients eligible for interbody fusion procedure. The inclusion criteria were grade 1 or 2 single level degenerative spondylolisthesis with mechanical back pain and neurological symptoms. Exclusion criteria were operation other than interbody fusion, previous spinal instrumentation, spinal tumor, fracture or infection pathology, failed to be followed up until one year or patients refused to be involved as a research subject.

All patients had already underwent conservative management for at least 3 months with no improvement in clinical symptoms. Pre-operative examination consists of anteroposterior, lateral and dynamic (flexion and extension) lumbar xray, non-contrast lumbar magnetic resonance imaging.

Evaluation of clinical parameter using back and leg visual analog scale (VAS), Oswestry Disability Index (ODI) and SF-36. All clinical parameter was evaluated before surgery, 3rd, 6th, and 12th months after surgery. Radiological examination of lumbar anteroposterior, lateral and dynamic xray were conducted concurrent with the clinical evaluation. On the 12th months after surgery we did CT scan to evaluate fusion.

Of the 170 patients eligible for TLIF procedure, 14 patients refused to be research subject. There were 80 patients underwent conventional MIS TLIF and 76 patients underwent unilateral biportal endoscopic lumbar interbody fusion (ULIF) procedure. On final followed up, there were 73 patients on conventional MIS TLIF group and 72 patients on ULIF group, the rest of the patients were loss to be followed up.

\section{Surgical Techniques For Unilateral Biportal Endoscopic Interbody Fusion}

Position, anesthesia and approach

Patients were positioned prone with 2 bolsters lying transverse on the chest and the anterior superior iliac spine. This position helps us opening the interlaminar window at the beginning of the procedure by jacking up the table and maintaining lumbar lordosis by neutraling the table at the end of procedure while inserting the interbody cages. In our center we mostly use general anesthesia for the procedure, even though in several patient with not good medical condition we sometimes use regional anesthesia. We think that general anesthesia provides more comfort for the patients and easier for mean arterial pressure maintenance during surgery.

Portal placement

We use biportal technique, in which the viewing portal and working are positioned at the level of pedicle above and below level of fusion. (Fig. 1) Two transverse half centimeters incision are made, for the right handed person, portal in the right hand side is used for working portal and in the left hand side is used for viewing portal. Working space on the subperiosteal space are created using periosteal elevator inserted on the working portal and scope trocar are introduced through the viewing portal. The triangulation maneuver is completed after trocar and periosteal elevator meet on the edge of lamina. The next step would be irrigating the water from the trocar into the working space and the water should be coming out from the working portal. (Fig. 2)

Flavectomy and foraminectomy 
Decompression are started with drilling the inferior edge lamina until insertion of flavum ligament, base of spinous process, and inner cortex of contralateral lamina until the contralateral facet joint. Drilling is done only to thin out and decorticate the outer cortex of the lamina. The next step would be doing the laminotomy and foraminectomy using combination of Kerrison punch and chisel to have solid bone graft for fusion. Foraminectomy is started by removing inferior articular process (IAP) until seeing base of superior articular process (SAP), medial part of SAP which is also the roof of lateral recess is also resected using either kerisson punch or chisel. The tip of SAP is also removed to create bigger space on the foraminal area for easier discectomy, endplate removal and cage insertion.

Flavectomy is started only after all the bony work finish, this is can be done either en bloc resection or piece by piece using Kerrison punch. (Fig. 3) We do not routinely do total flavectomy, it is depends complains of the patients, the severity of flavum thickening and location of the stenosis. Complete decompression would have sign of pulsating thecal sac, traversing nerve root and exiting nerve root.

Discectomy, endplate removal and cage insertion

Radiofrequency probe is used to expose the disc, usually there are a lot of epidural veins and some adhesion of the dura to the disc. Using the nerve retractor inserted from the working channel we can mobilize the traversing nerve root and the thecal sac towards medial side. Annulotomy is started using radiofrequency probe and continue with discectomy using shaver, currettes, forceps and endplate remover. (Fig. 4) Endplate preparation is finish until we can see multiple spot of bone bleeding, this bone bleeding can only be seen by the aid of endoscopy because the lens can go to the disc space. (Fig. 5) The next step would be trying the cage until the appropriate size, this cage trial are inserted through the working channel. (Fig. 6) Insertion of the cage for the right handed person is preferably done through the right side of the patients, especially on the level L45 or L5S1, because the working portal is located on the rostral side and in these level the intervertebral space are tilted towards the caudal side. (Fig. 7,8,9)

Pedicle screw insertion and listhesis reduction

Supplementation pedicle screw fixation are done using percutaneous technique under florouscopic guidance. (Fig. 10) In order to reduce the listhesis, there are several technique that we can do :

1. The rostral pedicle screw are inserted deeper in order to help reducing the listhesis.

2. Patients are position on extension by neutraling the table

3. Inserting the rod for cantilever maneuver by tightening the caudal screw and then tightening the rostral screw.

\section{Results}

All patients had diagnosis of degenerative spondylolisthesis and already underwent interbody procedure either conventional MIS-TLIF or ULIF. We did match control between both group in terms of age, sex, body mass index, operation level and history of smoking. The mean age for conventional MIS-TLIF were 52.3 years and 55.1 years on ULIF group which had a $p$ value of 0.016 . The ratio of male and female patient 0.66 on conventional MIS TLIF group and 0.8 on ULIF group with no statistic difference in both groups. The most common location for fusion procedure on degenerative spondylolisthesis patients was on L4-5 level with variation on body mass index level on all patients in both groups.

Pre-operative back and leg VAS, ODI, and SF-36 were similar in both groups with no difference in statistic $p$ value. All patients had a back VAS mean of 5.6, leg VAS mean of 4.5, mean ODI of 64.3, all SF-36 score showed no statistic difference in both groups. Post operation the ULIF group consistently showed better back VAS with a mean of 2.7, compared to conventional MIS-TLIF with the p-value on directly post op and 3rd months were 0.032 and 0.046 , but on the 6th and 12th months post operation the $p$ value were not significant. 
Leg visual analog scale did not differ between both groups, the p value on directly post op, 3rd, 6th and 12th months were $0.700,0.773,0.603$ and 0.067 . All the leg visual analog scale in both conventional MIS-TLIF and endoscopic interbody fusion showed improvement along the way. The leg pain improved significantly especially on the 6th months post operation. The mean VAS on ULIF group were 1.8 and on the conventional MIS-TLIF group were 2.1, majority of the patients showed only slight paresthesia as a residual symptom, but none of it were disturbing enough.

Patients with degenerative spondylolisthesis had a mean of ODI score $65 \%$ which showed moderate disability on the preoperation period. The ODI score improve significantly on both groups with the $p$ value of 0.0012 and 0.0013 on conventional MIS TLIF and ULIF respectively if we compared pre-and post-operation period. Comparison between both groups on 3rd, 6th and 12th months post op had no statistic difference. SF-36 also showed comparable outcome between both groups.

Fusion rate at first year post operation were $93.3 \%$ in the conventional MIS TLIF and $92.7 \%$ in the ULIF group with the $p$ value of 0.067 on both groups. Most the patients in both groups had grade III or IV fusion. On the conventional MIS TLIF group there were 2 patients with posterior cage migration, but it was not symptomatic. We only observed whether cage migration causing any symptoms.

There were several complications from the procedure. We had 3 patients with dural tear in the ULIF group, the tear was not repaired primarily but only cover with dural patch with no post operation neurologic deficit. There were 2 patients with infection in conventional MIS TLIF group. Both patients underwent debridement, removal of cage and maintenance of pedicle screw for stability. Cage subsidence were also occurred in 2 patients in conventional MIS TLIF groups.

Table 1

General Characteristic of Degenerative Spondylolisthesis Patients Underwent Operations

\begin{tabular}{|c|c|c|c|c|}
\hline & Conventional MIS-TLIF & ULIF & & P-Value \\
\hline & $N=73$ & $N=72$ & (Cl 95\%) & \\
\hline Age, years - means (SB) & $52.3(6.13)$ & $55,1(5.12)$ & $4,5(-1,9-10,9)$ & 0,160 \\
\hline Sex & & & & 0,130 \\
\hline Male & $28(37,5)$ & $26(62,5)$ & & \\
\hline Female & $45(63,2)$ & $46(36,8)$ & & \\
\hline Body Mass Index (BMI), $\mathrm{kg} / \mathrm{m}^{2}$-means (SB) & $24,8(3,42)$ & $23,6(3,67)$ & $1,2(-1,2-3,7)$ & 0,319 \\
\hline BMI Category & & & & 0,494 \\
\hline Normal & $39(40,0)$ & $40(60,0)$ & & \\
\hline Overweight & $30(66,7)$ & $29(33,3)$ & & \\
\hline Obese & $4(57,1)$ & $3(42,9)$ & & \\
\hline Smoking History & & & & 0,227 \\
\hline Yes & $11(36,4)$ & $17(63,6)$ & & \\
\hline No & $62(58,3)$ & $55(41,7)$ & & \\
\hline Operation Level & & & & 0,586 \\
\hline L3-4 & $10(11,42)$ & $8(10,52)$ & & \\
\hline L4-5 & $48(65,71)$ & $56(81,57)$ & & \\
\hline L5-S1 & $15(22,85)$ & $8(7,89)$ & & \\
\hline
\end{tabular}


Table 2

Comparison of visual analog scale between Conventional MIS TLIF and ULIF

\begin{tabular}{|c|c|c|c|c|}
\hline & $\begin{array}{l}\text { Conventional MIS TLIF } \\
\mathrm{N}=73\end{array}$ & $\begin{array}{l}\text { ULIF } \\
N=72\end{array}$ & $\begin{array}{l}\text { Mean Difference } \\
\text { (Cl 95\%) }\end{array}$ & P-Value \\
\hline \multicolumn{5}{|c|}{ Visual analog scale } \\
\hline \multicolumn{5}{|l|}{ Back } \\
\hline Pre operation & 5.4 & 5.7 & $0(-1-1)$ & 0.708 \\
\hline \multicolumn{5}{|c|}{ Post operation } \\
\hline Directly & 3.9 & 2.7 & $0(-1-1)$ & 0.032 \\
\hline 3 months & 2.4 & 1.9 & $0(-1-1)$ & 0.046 \\
\hline 6 months & 1.6 & 1.7 & $0(-1-1)$ & 0.660 \\
\hline 12 months & 0.9 & 0.8 & $0(0-1)$ & 0.386 \\
\hline \multicolumn{5}{|l|}{ Leg } \\
\hline Pre operation & 4.5 & 4.6 & $0(-1-1)$ & 0.909 \\
\hline \multicolumn{5}{|l|}{ Post operation } \\
\hline Directly & 4.6 & 4.6 & $0(0-1)$ & 0.700 \\
\hline 3 months & 3.6 & 3.7 & $0(0-1)$ & 0.773 \\
\hline 6 months & 1.8 & 2.1 & $1(0-1)$ & 0.603 \\
\hline 12 months & 0.8 & 0.7 & $1(0-2)$ & 0.067 \\
\hline
\end{tabular}

Table 3

Comparison of Oswestry Disability Index between Conventional MIS TLIF and ULIF

\begin{tabular}{|c|c|c|c|c|}
\hline & Conventional MIS TLIF & ULIF & \multirow{2}{*}{$\begin{array}{l}\text { Mean Difference } \\
\text { (Cl 95\%) }\end{array}$} & \multirow[t]{2}{*}{ P Value } \\
\hline & $N=73$ & $N=72$ & & \\
\hline \multicolumn{5}{|c|}{ Oswestry Disability Index } \\
\hline Pre operation & $62(56.5-70.5)$ & $60(52-63.5)$ & $6(-2-14)$ & 0.103 \\
\hline \multicolumn{5}{|l|}{ Post operation } \\
\hline Directly & $54(37-49)$ & $41(49-60.5)$ & $11(-3-17)$ & 0.045 \\
\hline 3 months & $16(5.5-14.5)$ & $12(8-32.5)$ & $-4(-12-2)$ & 0.232 \\
\hline 6 months & $12(4-12.5)$ & $8(4-19)$ & $-2(-8-4)$ & 0.483 \\
\hline 12 months & $8(1.5-10)$ & $6(3.5-17.5)$ & $-3(-10-2)$ & 0.184 \\
\hline
\end{tabular}


Table 4

Comparison of SF-36 score between MIS TLIF and ULIF

\begin{tabular}{|c|c|c|c|c|c|c|c|c|c|}
\hline \multirow[t]{2}{*}{ SF-36 } & \multicolumn{3}{|l|}{3 months } & \multicolumn{3}{|l|}{6 months } & \multicolumn{3}{|l|}{12 months } \\
\hline & $\begin{array}{l}\text { Coventional } \\
\text { MIS TLIF }\end{array}$ & ULIF & $\begin{array}{l}\mathrm{P} \\
\text { Value }\end{array}$ & $\begin{array}{l}\text { Coventional } \\
\text { MIS TLIF }\end{array}$ & ULIF & $\begin{array}{l}\mathrm{P} \\
\text { Value }\end{array}$ & $\begin{array}{l}\text { Coventional } \\
\text { MIS TLIF }\end{array}$ & ULIF & $\begin{array}{l}\mathrm{P} \\
\text { Value }\end{array}$ \\
\hline PF & $66.5 \pm 4.9$ & $65.2 \pm 4.1$ & 0.067 & $70.3 \pm 5.4$ & $71.5 \pm 4.9$ & 0.071 & $73.3 \pm 5.0$ & $69.4 \pm 4.9$ & 0.070 \\
\hline RFP & $57.4 \pm 7$ & $37.4 \pm 6.8$ & 0.078 & $72.4 \pm 6.9$ & $63.5 \pm 7.0$ & 0.073 & $68.9 \pm 6.9$ & $66.3 \pm 7.1$ & 0.075 \\
\hline $\begin{array}{l}\text { Bodily } \\
\text { pain }\end{array}$ & $55.8 \pm 4.1$ & $53.5 \pm 3.7$ & 0.066 & $61.8 \pm 4.3$ & $64.5 \pm 7.9$ & 0.086 & $65.7 \pm 5.4$ & $66.4 \pm 6.7$ & 0.088 \\
\hline $\begin{array}{l}\text { General } \\
\text { health }\end{array}$ & $65.6 \pm 3.9$ & $61.2 \pm 3.2$ & 0.079 & $66.8 \pm 4.8$ & $67.9 \pm 5.4$ & 0.081 & $73.8 \pm 4.9$ & $75.4 \pm 6.9$ & 0.069 \\
\hline Vitality & $76.3 \pm 5.9$ & $59.5 \pm 4.2$ & 0.088 & $69.5 \pm 3.7$ & $72.4 \pm 5.1$ & 0.075 & $73.3 \pm 4.6$ & $73.4 \pm 5.7$ & 0.083 \\
\hline SRF & $75.6 \pm 5.4$ & $78.3 \pm 5.1$ & 0.083 & $87.6 \pm 5.0$ & $88.4 \pm 6.7$ & 0.089 & $82.4 \pm 5.9$ & $83.4 \pm 5.3$ & 0.086 \\
\hline ERF & $75.6 \pm 6.5$ & $70.5 \pm 8.3$ & 0.072 & $84.5 \pm 3.4$ & $83.8 \pm 2.1$ & 0.076 & $93.3 \pm 5.3$ & $92.1 \pm 4.2$ & 0.092 \\
\hline $\begin{array}{l}\text { Mental } \\
\text { health }\end{array}$ & $77.2 \pm 3.5$ & $70.3 \pm 4.5$ & 0.075 & $77.4 \pm 3.5$ & $79.3 \pm 4.5$ & 0.062 & $83.2 \pm 4.3$ & $82.1 \pm 6.3$ & 0.068 \\
\hline PCS & $42.8 \pm 12.6$ & $40.2 \pm 11.5$ & 0.077 & $43.5 \pm 9.6$ & $44.5 \pm 7.2$ & 0.055 & $48.0 \pm 11.0$ & $48.7 \pm 7.3$ & 0.077 \\
\hline MCS & $51.6 \pm 12.9$ & $48.6 \pm 12.9$ & 0.079 & $50.6 \pm 12.1$ & $51.3 \pm 5.6$ & 0.086 & $55.1 \pm 13.8$ & $54.8 \pm 10.4$ & 0.088 \\
\hline
\end{tabular}

Table 5

Radiological outcome of Lumbar Interbody Fusion

\begin{tabular}{|c|c|c|c|c|c|}
\hline & Overall & Conventional MIS TLIF & ULIF & P Value & Power \\
\hline & $N=145$ & $N=73$ & $N=72$ & & \\
\hline Fusion & $135(92.8)$ & $67(47.7)$ & $68(52.2)$ & 0.076 & $83 \%$ \\
\hline Not fusion & $10(7.18)$ & $6(50.0)$ & $4(50.0)$ & & \\
\hline Fusion Grading & & & & 0.072 & \\
\hline I & $4(8.6)$ & $2(33.3)$ & $2(66.7)$ & & \\
\hline II & $6(14.3)$ & $3(66.7)$ & $3(33.3)$ & & \\
\hline III & $30(40.0)$ & $15(50.0)$ & $15(50.0)$ & & \\
\hline IV & $105(37.1)$ & $53(47.2)$ & $52(52.8)$ & & \\
\hline
\end{tabular}

\section{Discussion}

Conventional open surgery for spinal stenosis with instability still remain the gold standard for achieving complete decompression and fusion. This kind of procedure, although remain the workhorse for management of lumbar degenerative condition, is not without disadvantages such as muscle injury which could cause loss of posterior tension band, epidural fibrosis after the operation that could cause re-stenosis in the future, loss of blood during operation and long hospital stay which result in long functional recovery rehabilitation phase and expensive patient and hospital care.

Minimal invasive spine surgery has been developed to encounter such of problems, development of minimal invasive spine surgery is very extensive in the last 2 decades from simple discectomy, decompression only procedure and fusion procedure 
using air based medium surgery and recently water based medium surgery.[5, 9] Water based endoscopic procedure regain popularity due to easier to control bleeding, clearer image compared with air medium surgery and mobility of the endoscope and instrument which give wider working space and better evaluation of decompression and preparation of fusion bed in the case of fusion surgery. $[4,14]$

In this paper we tried to evaluate the result of biportal endoscopic interbody fusion compared with conventional MIS-TLIF. Using biportal endoscopic fusion we tried to preserve as much as possible the paravertebral muscle and removing the bony structure at the very minimum. This technique uses the advantage of endoscopic procedure combined with the standard working spine instrument such as kerisson punch, reamers, nerve retractors and etc. Compared with the uniportal endoscopic technique, in which the optics and working portal shares the space, the biportal technique has more mobility and bigger working space which makes preparation for fusion becomes easier.

Conventional MIS-TLIF still has higher post op back pain compared with ULIF procedure. This is probably due to more muscle injury in the conventional MIS-TLIF procedure. Unilateral biportal endoscopic lumbar interbody fusion procedure also has advantage in the procedure of decompression, we can see clearly the space for lateral recess, foraminal area without the need to increase tissue destruction as in conventional MIS-TLIF procedure. In conventional MIS-TLIF, sometimes we need bilateral approach in order to achieved adequate decompression.

Endoscopic spine procedure which seems easy on the paper, has it's own learning curve.[15-17] The biportal endoscopic technique needs triangulation because of separate working and viewing portal just like arthroscopy, surgeon familiar with arthroscopy can adapt more easily. The technique also require single handed instrument handling which cause delicate procedure becomes more complex and complication such as dural tear and nerve root injury could happen especially for beginner.

Endplate preparation is of importance in interbody fusion procedure. Endoscopic procedure enables us to view directly into the intervertebral space and remove remaining nucleus and annulus after blind removal.[10] Bleeding from endplate is the sign of complete endplate preparation. $[5,9,18]$ In order to see bony bleeding with other procedure such as conventional MIS-TLIF, open TLIF, OLIF, and ALIF are usually impossible due to limited working space. We usually just feel using the reamer whether it is already the endplate yet. In order to achieve solid fusion we always insert bone chips combination of autograft from lamina and facet joint and allograft in the form of demineralized bone matrix using special funnel inserted into the disc space.[19]

Biportal endoscopic procedure is not without disadvantages, during the process we encounter several problems. Dural tear, even though rare, happen in 5 cases with severe flavum ligament thickening. We manage that complication using dural patch without direct primary repair, the result of this management were quite good without neurologic deficit.[20] Epidural hematoma is another complication that happen during endoscopic procedure, especially procedure with quite a lot of bony work, 3 cases of post operation epidural hematoma. This is probably due to oozing from the bone and intact posterior tension band which result in increasing pressure inside the epidural space, even though it could resolve by it self but it could cause pain and discomfort to the patient after the procedure.[21]

\section{Conclusion}

Unilateral biportal endoscopic procedure gives surgeons another option in achieving decompression of the nerve and fusion. This procedure, even though still needs improvement, can be the next future standard in managing degenerative lumbar spine condition. However, the long term follow up and larger studies is needed are needed to further evaluate the procedure.

\section{Abbreviations}


VAS : Visual analog scale ; ODI : Oswestry Disability Index ; MIS-TLIF : Minimal invasive lumbar interbody fusion ; ULIF :

Unilateral Biportal Endoscopic Lumbar Interbody Fusion ; IAP : Inferior Articular Process ; SAP : Superior Articular Process

\section{Declarations}

\section{Ethics Approval and Consent to Participate}

This research had already been approved by ethical committee in Fatmawati General Hospital Jakarta

\section{Consent for publication}

My manuscripts does not contain any individual person data. The co-authors consented to the publication of this article

\section{Availability of data and materials}

There is no other supporting data.

\section{Competing Interest}

The authors declare that they have no competing interest

\section{Funding}

None

\section{Author Contribution}

Asrafi Rizki Gatam : Performing the surgery, writing the paper.

Ajiantoro : Collecting data, writing the paper

Omar Luthfi : Collecting Data, performing surgery

Harmantya Mahadhipta : Performing the surgery

Luthfi Gatam : Performing the surgery, designing the study, revising the study

\section{Acknowledgement}

None

\section{References}


1. Derman PB, Albert TJ. Interbody Fusion Techniques in the Surgical Management of Degenerative Lumbar Spondylolisthesis. Curr Rev Musculoskelet Med Current Reviews in Musculoskeletal Medicine. 2017;10:530-8.

2. Gokaslan ZL. A brief history of endoscopic spine surgery. Neurosurg Focus. 2016;40.

3. Wegener B, Ruetten S. The Current State of Endoscopic Disc Surgery: Review of Controlled Studies Comparing FullEndoscopic Procedures for Disc Herniations to Standard Procedures. 2013;335-44.

4. Kim M, Lee S, Kim HS, Park S, Shim SY, Lim DJ. A Comparison of Percutaneous Endoscopic Lumbar Discectomy and Open Lumbar Microdiscectomy for Lumbar Disc Herniation in the Korean: A Meta-Analysis. Biomed Res Int. Hindawi; 2018;2018.

5. Jin M, Zhang J, Shao H, Liu J, Huang Y. Percutaneous transforaminal endoscopic lumbar interbody fusion for degenerative lumbar diseases: A consecutive case series with mean 2-year follow-up. Pain Physician. 2020;23:165-74.

6. 10.1016/j.clineuro.2018.10.017

Liu C, Zhou Y. Percutaneous endoscopic lumbar discectomy and minimally invasive transforaminal lumbar interbody fusion for massive lumbar disc herniation. Clin Neurol Neurosurg [Internet]. Elsevier B.V.; 2019;176:19-24. Available from: https://doi.org/10.1016/j.clineuro.2018.10.017.

7. Kolcun JPG, Brusko GD, Basil GW, Epstein R, Wang MY. Endoscopic transforaminal lumbar interbody fusion without general anesthesia: Operative and clinical outcomes in 100 consecutive patients with a minimum 1-year follow-up. Neurosurg Focus. 2019;46:1-5.

8. $10.1080 / 17434440.2019 .1610388$

Ahn Y, Youn MS, Heo DH. Endoscopic transforaminal lumbar interbody fusion: a comprehensive review. Expert Rev Med Devices [Internet]. Taylor \& Francis; 2019;16:373-80. Available from:

https://doi.org/10.1080/17434440.2019.1610388.

9. León JFR, Ardila ÁS, Rugeles Ortíz JG, Martínez CR, Alonso Cuéllar GO, Infante J, et al. Standalone lordotic endoscopic wedge lumbar interbody fusion (LEW-LIF ${ }^{\mathrm{TM}}$ ) with a threaded cylindrical peek cage: report of two cases. J Spine Surg. 2020;6:275-85.

10. Park MK, Park SA, Son SK, Park WW, Choi SH. Correction to: Clinical and radiological outcomes of unilateral biportal endoscopic lumbar interbody fusion (ULIF) compared with conventional posterior lumbar interbody fusion (PLIF): 1year follow-up (Neurosurgical Review, (2019), 42, 3, (753-761), 10.10. Neurosurg Rev. Neurosurgical Review; 2019;42:763.

11. 10.1016/j.wneu.2018.05.049

Yang Y, Liu ZY, Zhang LM, Pang M, Chhantyal K, Wu W, Bin, et al. Microendoscopy-Assisted Minimally Invasive Versus Open Transforaminal Lumbar Interbody Fusion for Lumbar Degenerative Diseases: 5-Year Outcomes. World Neurosurg [Internet]. Elsevier Inc.; 2018;116:e602-10. Available from: https://doi.org/10.1016/j.wneu.2018.05.049.

12. Kim JE, Choi DJ. Unilateral biportal endoscopic spinal surgery using a $30^{\circ}$ arthroscope for L5-S1 foraminal decompression. CiOS Clin Orthop Surg. 2018;10:508-12.

13. Kim JE, Choi DJ, Park EJ. Clinical and radiological outcomes of foraminal decompression using unilateral biportal endoscopic spine surgery for lumbar foraminal stenosis. CiOS Clin Orthop Surg. 2018;10:439-47.

14. Ruetten S, Komp M, Merk H, Godolias G. Full-Endoscopic Interlaminar and Transforaminal Lumbar Discectomy Versus Conventional Microsurgical Technique. Spine (Phila Pa 1976) [Internet]. 2008;33:931-9. Available from:

http://content.wkhealth.com/linkback/openurl?sid=WKPTLP:landingpage\&an=00007632-200804200-00002.

15. Hsu HT, Chang SJ, Yang SS, Chai CL. Learning curve of full-endoscopic lumbar discectomy. Eur Spine J. 2013;22:72733.

16. Choi CM, Chung JT, Lee SJ, Choi DJ. How I do it? Biportal endoscopic spinal surgery (BESS) for treatment of lumbar spinal stenosis. Acta Neurochir (Wien). 2016;158:459-63. 
17. Anichini G, Landi A, Caporlingua F, Beer-Furlan A, Brogna C, Delfini R, et al. Lumbar Endoscopic Microdiscectomy: Where Are We Now? An Updated Literature Review Focused on Clinical Outcome, Complications, and Rate of Recurrence. Biomed Res Int. 2015;2015.

18. Heo DH, Son SK, Eum JH, Park CK. Fully endoscopic lumbar interbody fusion using a percutaneous unilateral biportal endoscopic technique: Technical note and preliminary clinical results. Neurosurg Focus. 2017;43:1-6.

19. Gatam AR, Gatam L, Tobing SDL. Comparison of clinical and radiological outcomes of lumbar interbody fusion using a combination of hydroxyapatite and demineralized bone matrix and autografts for lumbar degenerative spondylolisthesis. Asian Spine J. 2017;11:706-14.

20. 10.1016/j.wneu.2020.01.080

Park HJ, Kim SK, Lee S, Kim W, Han S, Kang SS. Dural Tears in Percutaneous Biportal Endoscopic Spine Surgery: Anatomical Location and Management [Internet]. World Neurosurg. Elsevier Inc.; 2020. Available from: https://doi.org/10.1016/j.wneu.2020.01.080.

21. 10.1016/j.wneu.2019.05.141

Kim JE, Choi DJ, Kim MC, Park EJ. Risk Factors of Postoperative Spinal Epidural Hematoma After Biportal Endoscopic Spinal Surgery. World Neurosurg [Internet]. Elsevier Inc; 2019;129:e324-9. Available from:

https://doi.org/10.1016/j.wneu.2019.05.141.

\section{Figures}

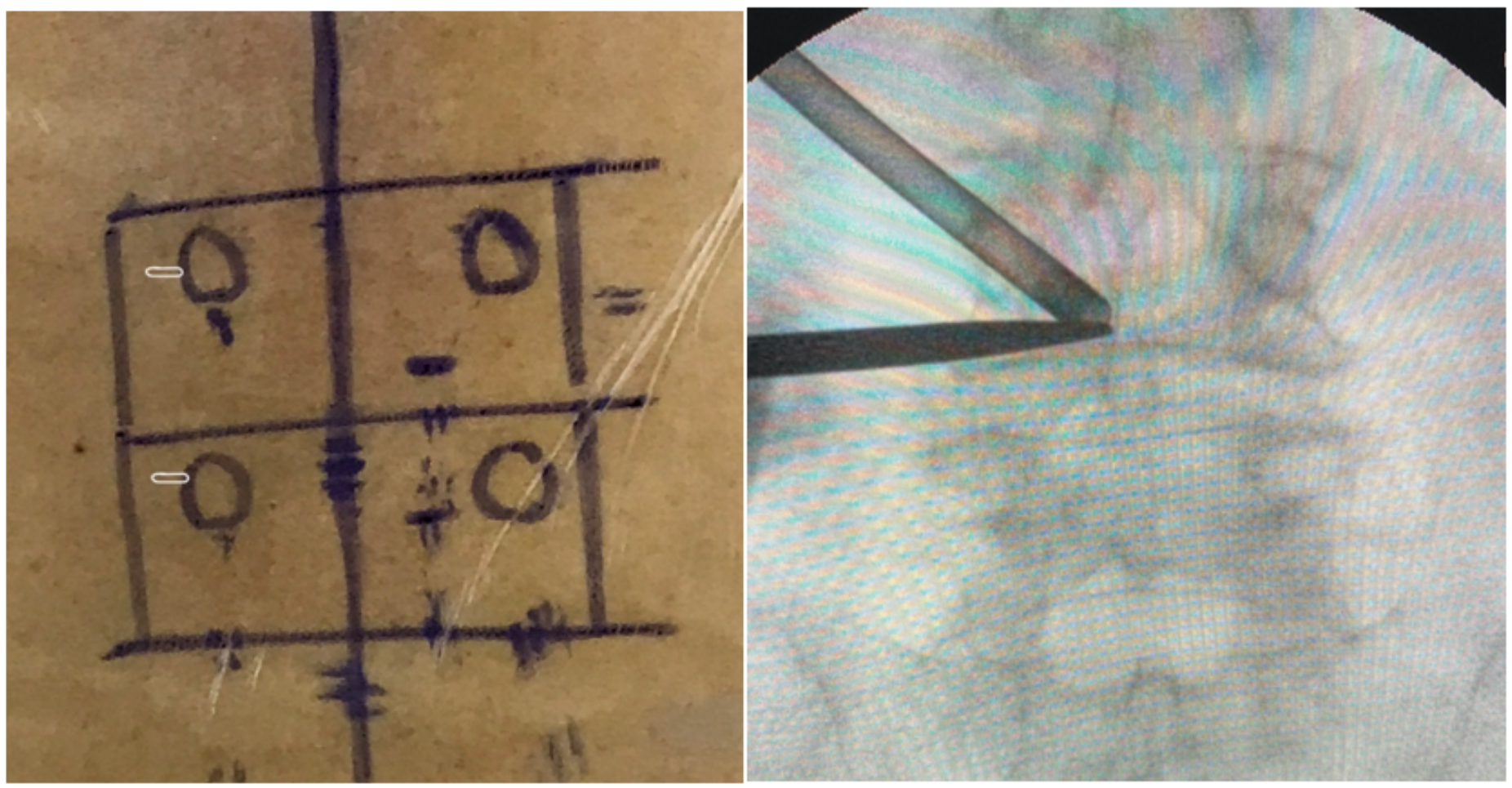

\section{Figure 1}

Location of incision at the level of pedicle and Triangulation of working and viewing portal above the lamina 


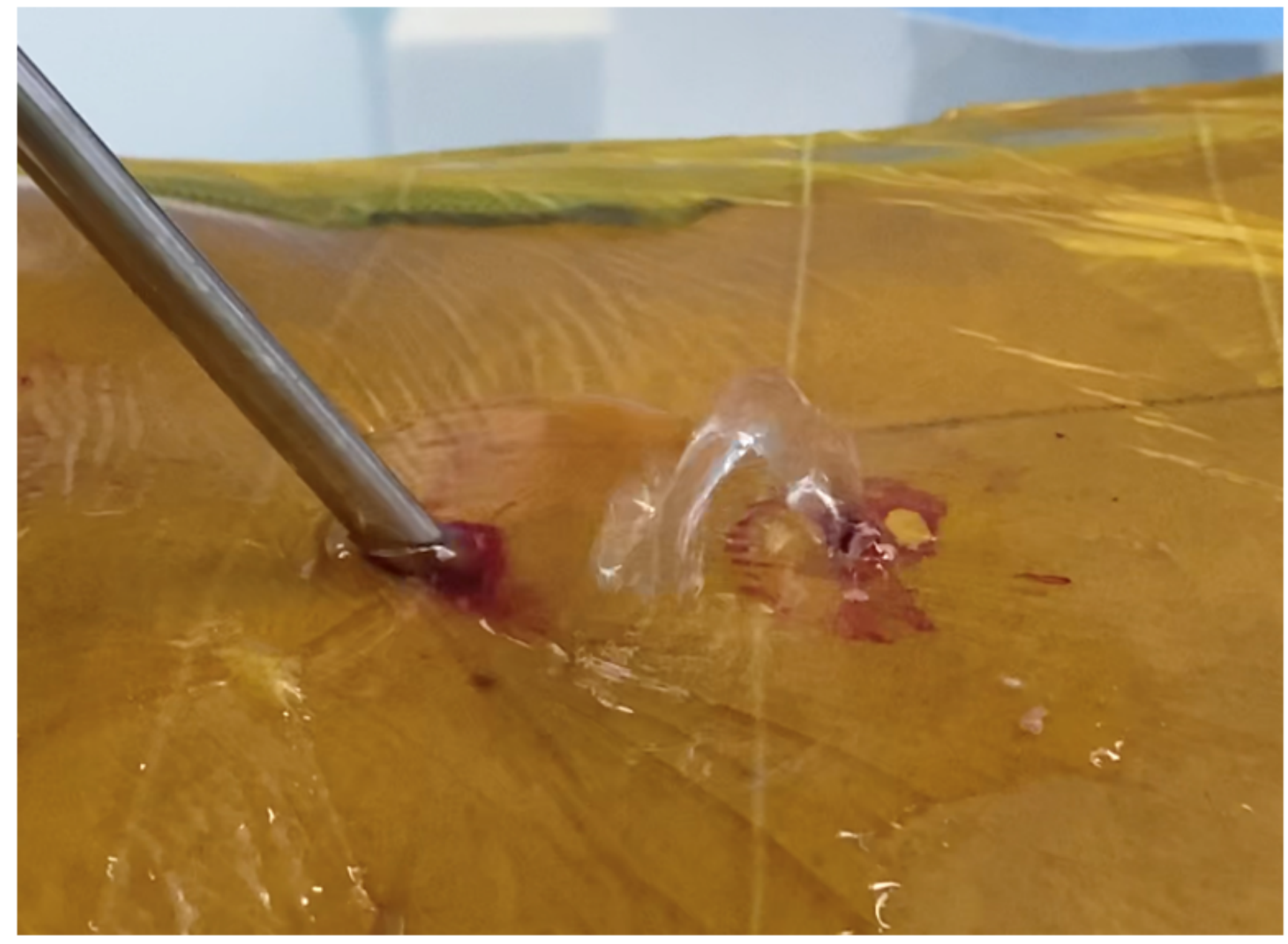

\section{Figure 2}

Water flow from viewing portal to working portal

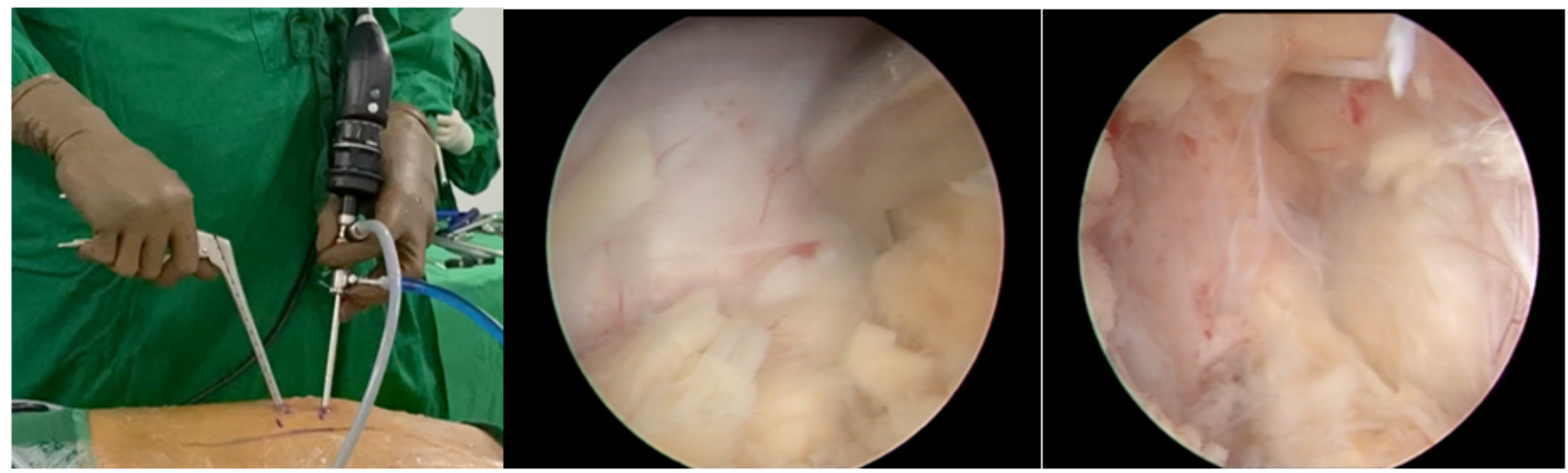

\section{Figure 3}

Working position using unilateral biportal endoscopy, Flavectomy piece by piece using kerisson punch, and contralateral decompression 


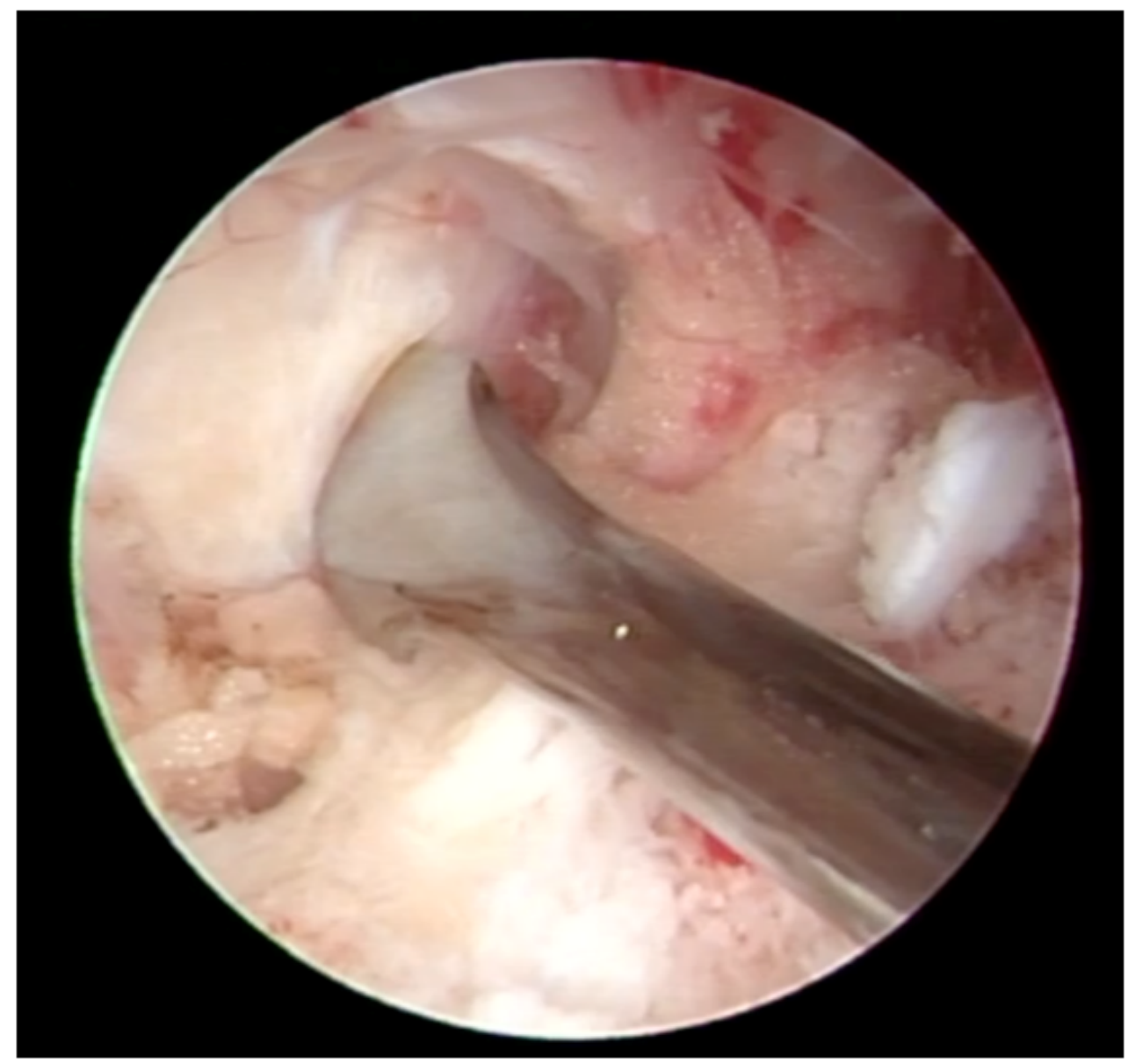

Figure 4

Annulotomy using annular cutter

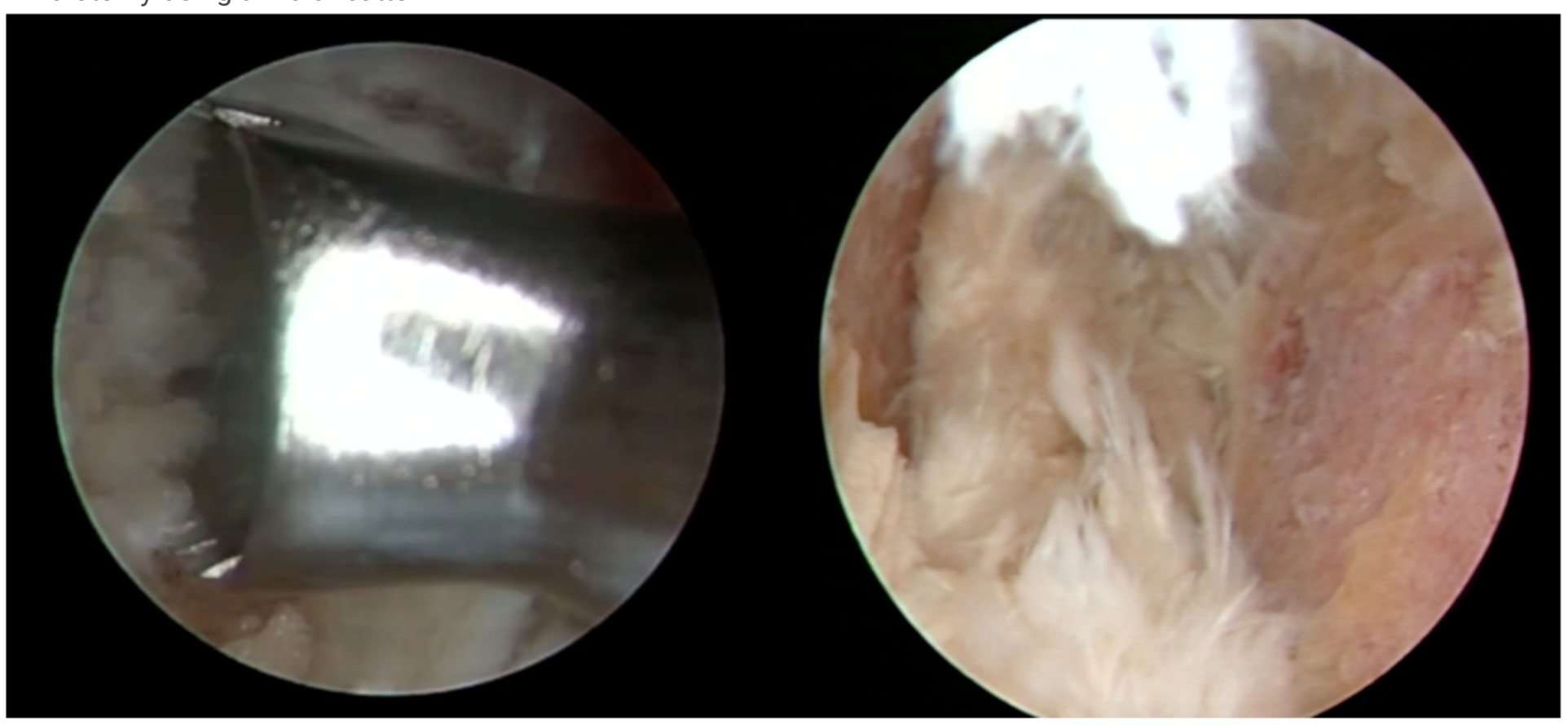

Figure 5

a. Insertion of curette to prepare the endplate, b. Remnant of annulus and endplate after curretage 


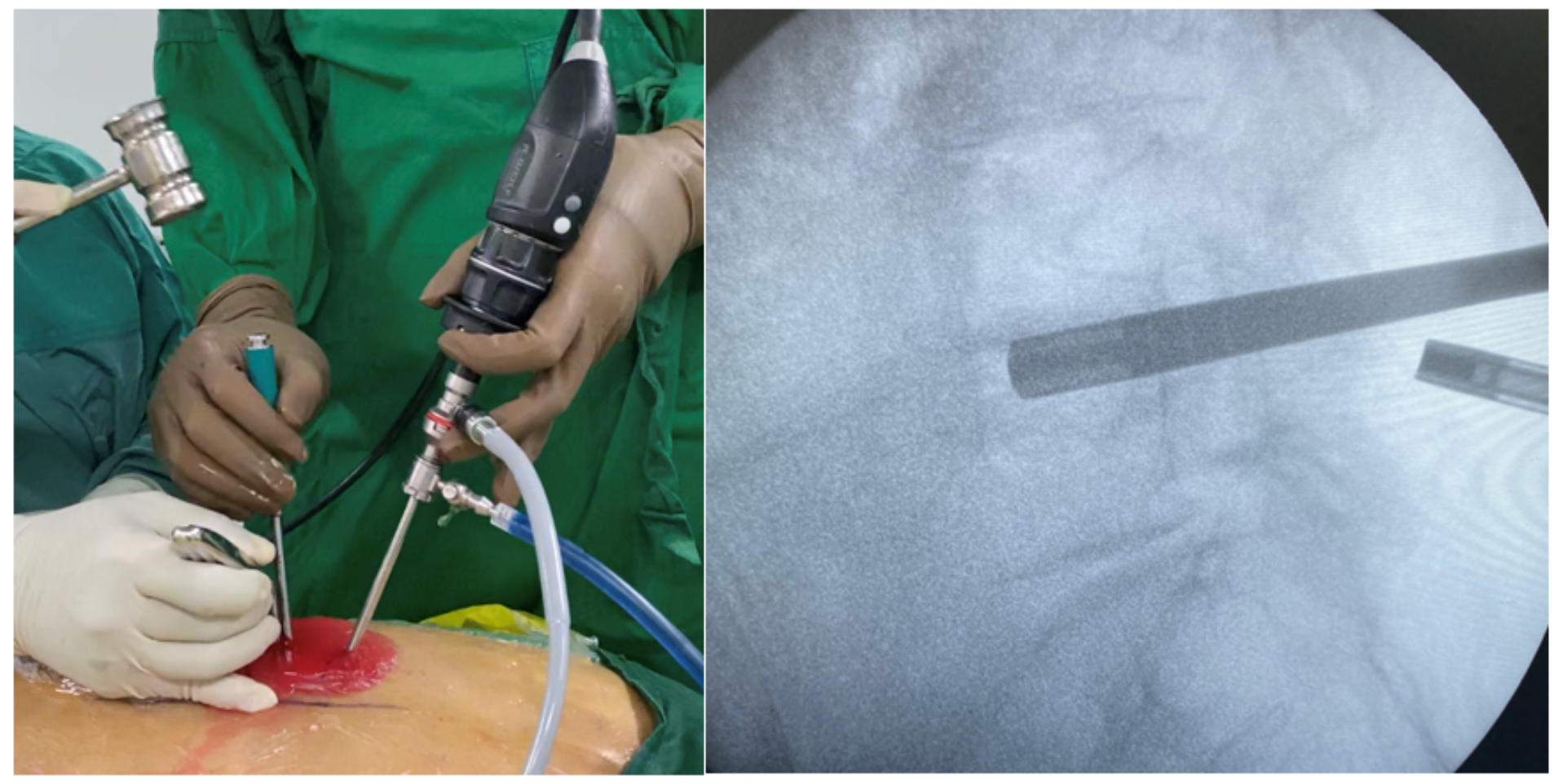

Figure 6

Insertion of reamer under fluoroscopic view

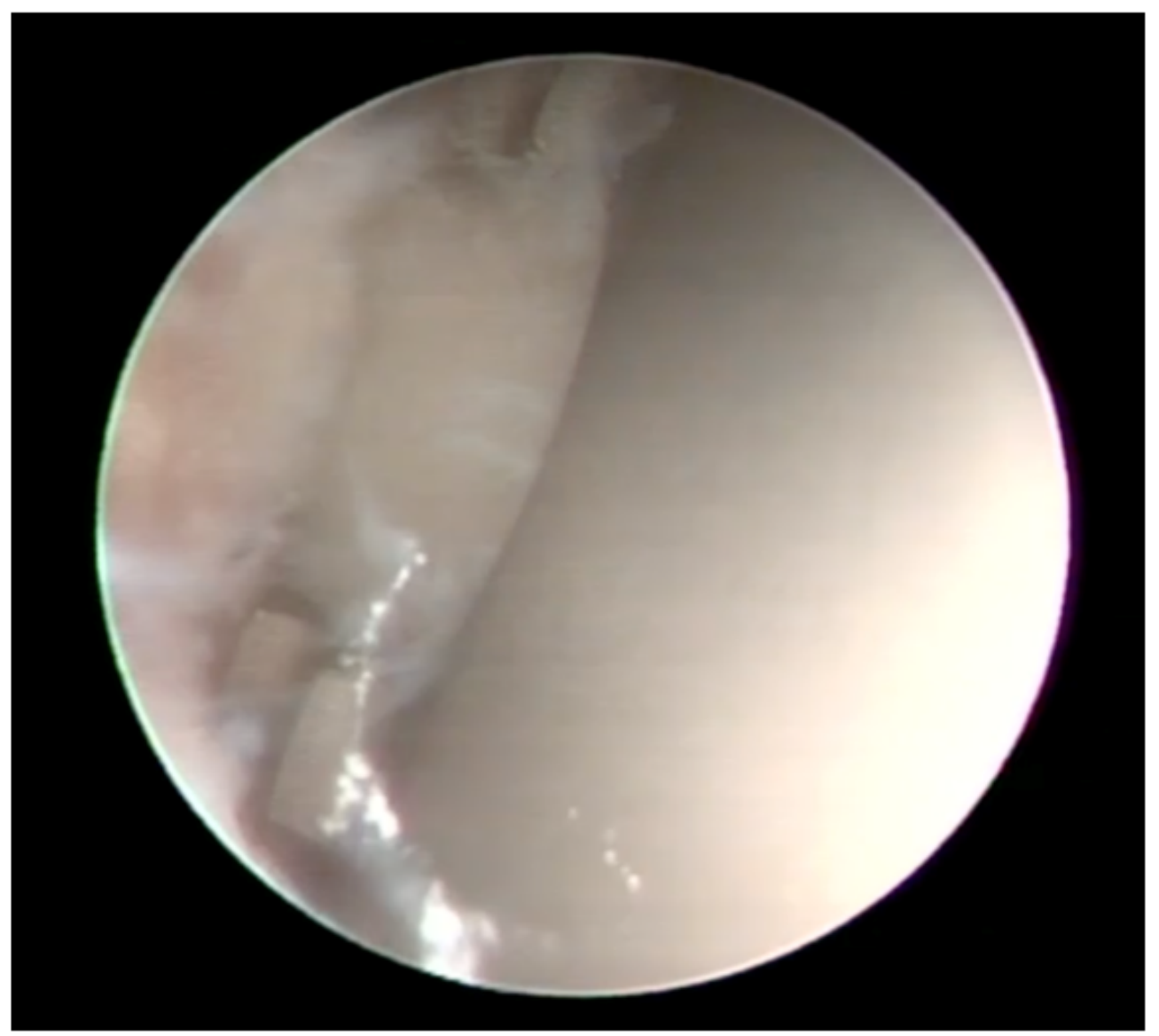

Figure 7 


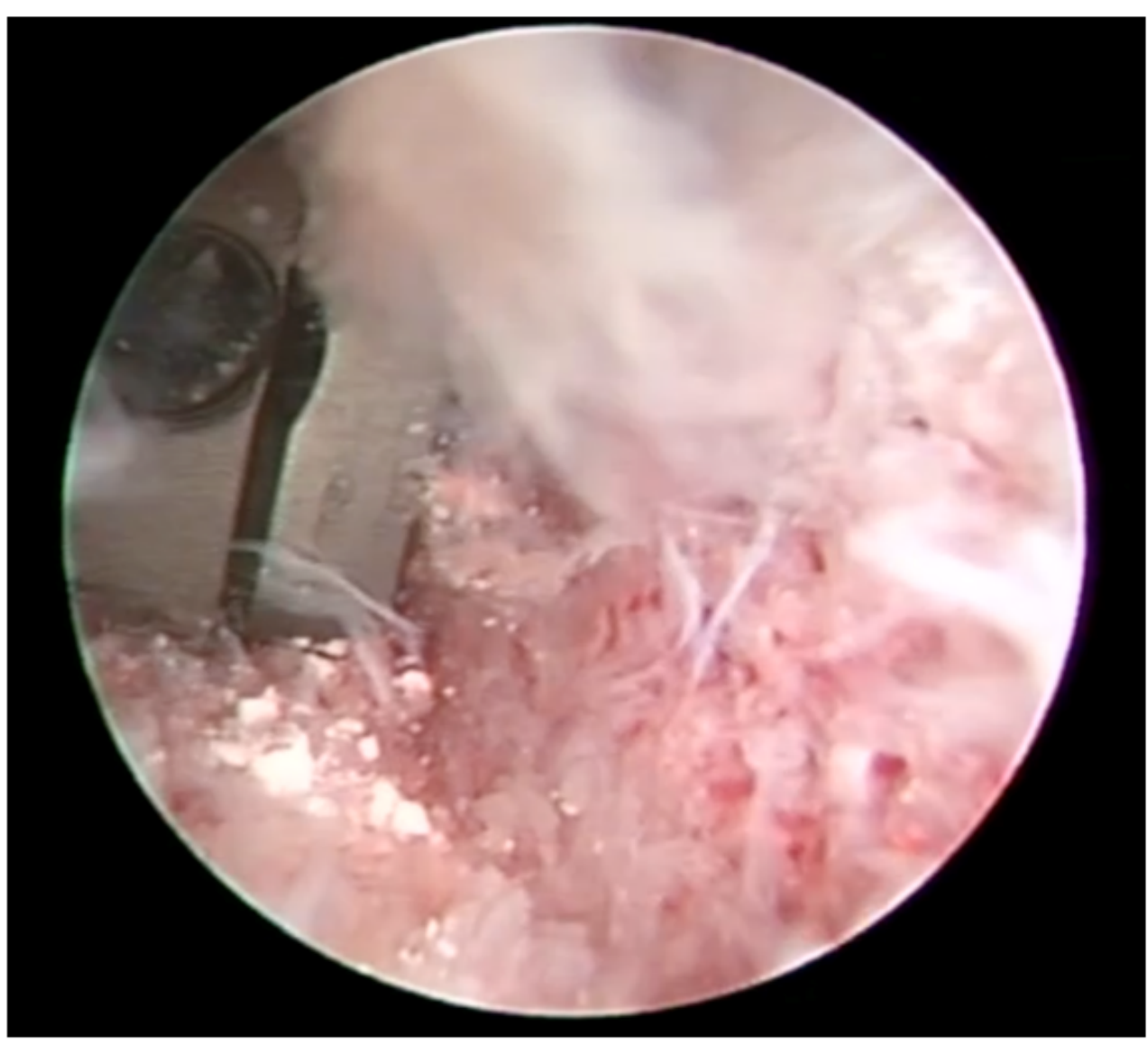

Figure 8

Cage inside the disc space

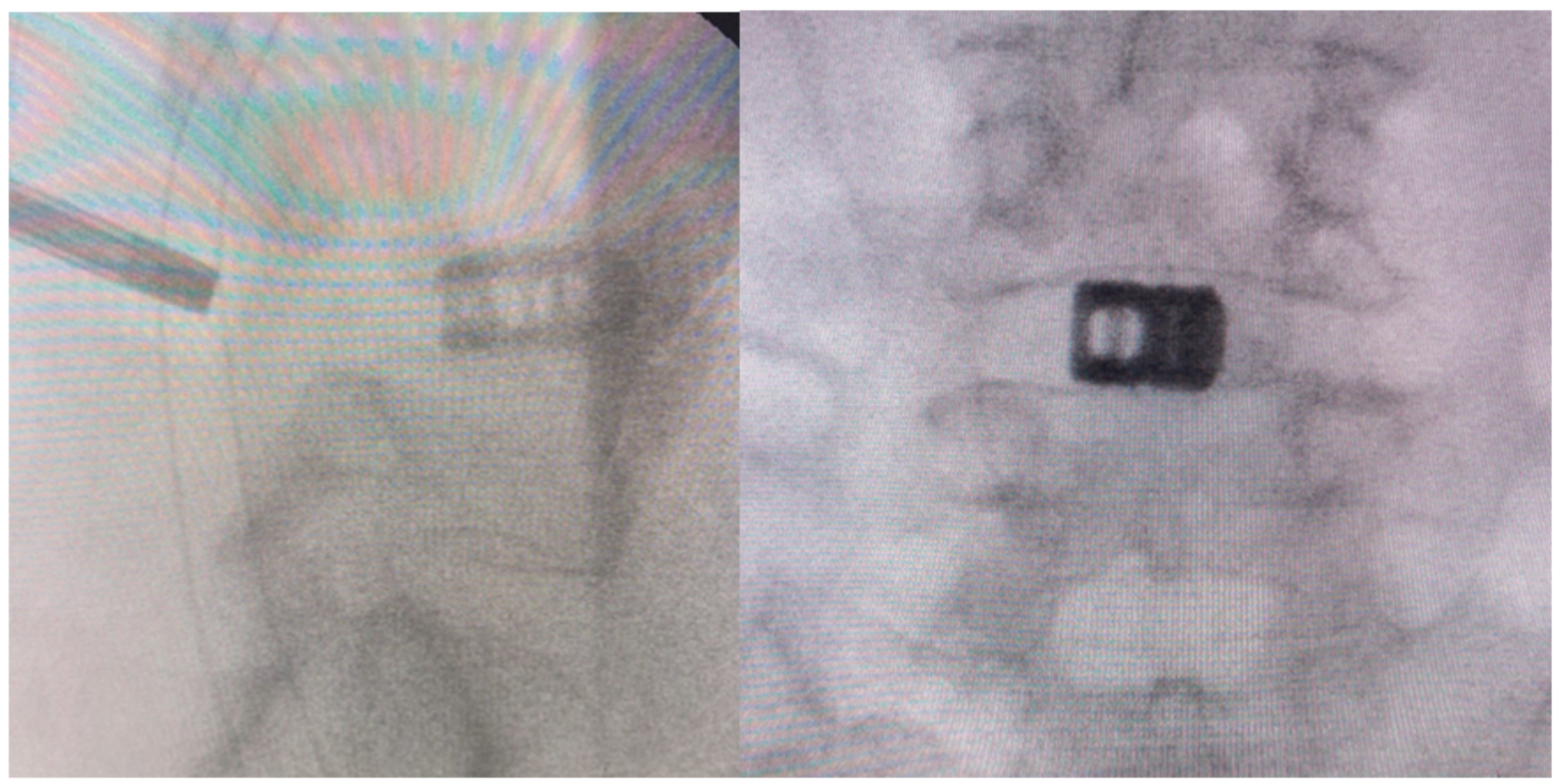

Figure 9 
Interbody cage inside the disc space

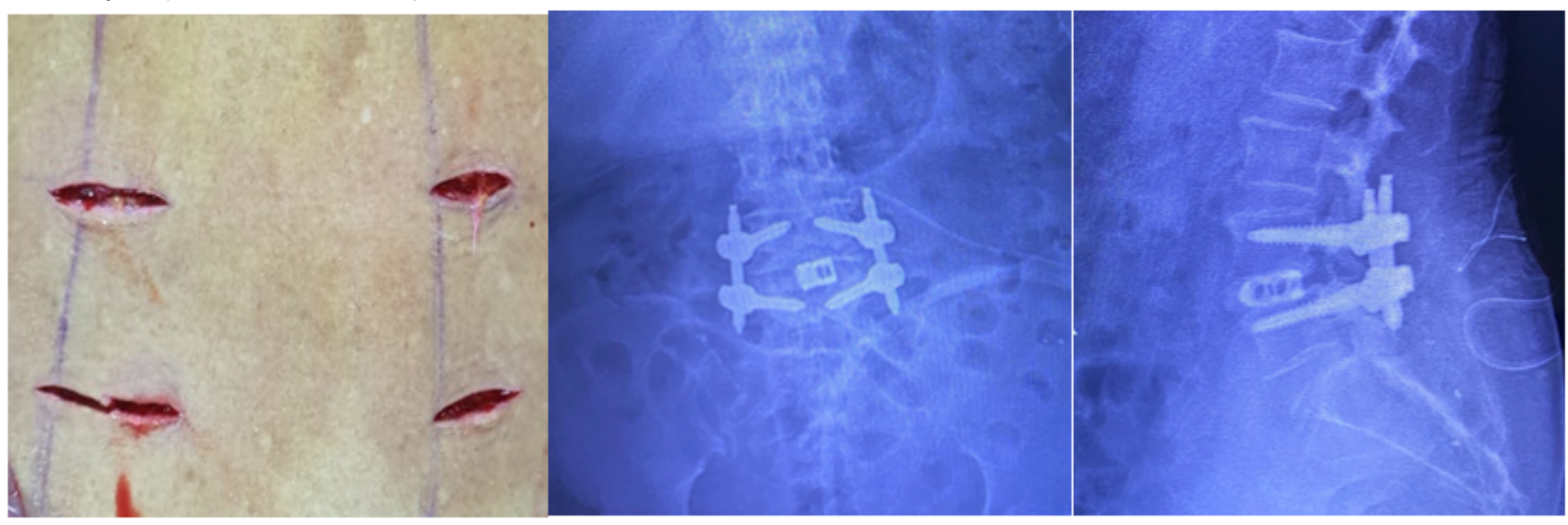

Figure 10

Skin Incision and Post op xray 